\title{
Bridging the Digital Divide in Ethnic Minority Older Adults: an Organisational Qualitative Study
}

\author{
Jyoti Choudrie $^{1}$ (D) $\cdot$ Efpraxia Zamani $^{2} \cdot$ Chike Obuekwe $^{1}$
}

Accepted: 11 March 2021 / Published online: 15 May 2021

(C) The Author(s) 2021, corrected publication 2021

\begin{abstract}
This paper aims to explore and understand the digital divide in older adults when accepting and using smart devices within an organization. Using an in-depth single case study, the digital divide is explored and understood using technology-mediated learning for older adults when using smart devices; ie. tablet devices. The case study is based on a group of educated, older Indian adult volunteers at a local Punjabi radio station. A qualitative approach used the data collection techniques of interviews, observations, informal conversations and reference to archival documents and interpretivism for analysis. Our findings revealed that older adults with ailments have shorter lives, contrary to popular perception, can be very active in their communities, are able to use basic IT and are willing to use technology when it leads to significant tangible or intangible benefits without considering the remaining time of their lives. Contributions for policymakers and industry are also offered in this paper.
\end{abstract}

Keywords Older adults $\cdot$ Qualitative study $\cdot$ Interpretivism $\cdot$ Internet self-efficacy $\cdot$ Learning models

\section{Introduction}

Medical advances have improved individual's quality of life; thereby, allowing older adults to live better lives and work for longer (Ghahramani \& Wang, 2019). Non-government organizations, such as the Organisation for Economic Co-operation and Development (OECD) (2018) have found that governments can harness the potential of older workers, to raise additional tax revenues and increase spending power, which in turn boosts output (Wood, 2018). Organisations can employ older professionals to access and maintain the knowledge acquired over the years; thereby ensuring that the tacit and explicit knowledge is treasured (Gupta \& Bostrom, 2009).

Technological progress is also often central for improvements in human development (Martinez-Garcia, 2013; United Nations Development Programme, 2001). Information and

The author team would like to emphasise that Efpraxia Zamani is the second author as she had a larger role in terms of writing, analysing and preparing the findings of this manuscript. Chikelue Chike Obuekwe assisted with some of the data collection.

Jyoti Choudrie

j.choudrie@herts.ac.uk; jyotichoudrie@gmail.com

1 Hertfordshire Business School, University of Hertfordshire, Hatfield, Hertfordshire AL10 9EU, UK

2 Information School, University of Sheffield, Room 209a, Regent Court, 211 Portobello, Sheffield S1 4DP, UK
Communication Technologies (ICTs) such as, mobile and smart devices and Internet of Things (IoT) have emerged since the advent of the internet and broadband and proliferated the workplace, which has transformed it. Smart devices, such as smartphones, smartwatches, tablet devices and other Internetenabled portable devices, allow unprecedented access to information and to a myriad of applications (Marikyan et al., 2019). When considering adoption in the general public, it tends to be faster among persons who are more risk-oriented, less conservative, better integrated in society, younger, better educated and better-off (Rogers, 2003).

Although many older adults are actively using smart devices, many still encounter difficulties when adopting them and keeping up with the pace of technological advances (Choudrie \& Vyas, 2014); thereby, widening the digital divide (Hwang \& Nam, 2017). Such interpretations of the digital divide encapsulate implicit ideas of IT use, ageing, education and the use of IT by older adults (Kampfen \& Maurer, 2018; Schleife, 2010), but there are other issues to consider when determining this digital divide. First, this discourse focuses on the value that the use of IT in older adults has for society and their communities. This implies that it ignores what value IT could have for the older adults themselves (Neven \& Peine, 2017). Second, it implies that it is ageing and what this entails; eg. ailments that prohibits older adults from using IT; thus, framing older adults as frail and often incompetent (Suopajärvi, 2015). Third, it uncritically assumes that nonuse is a deficiency that needs to be addressed, and that 
everyone, irrespective of their personal situation, desires to use IT and should be a potential user (Wyatt, 2003). As internet proliferation and penetration occurs, policies and steps are being taken by governments and organizations to encourage all age groups to use online products and services, but practically and in applied situations, gaps in acceptance and usage in users still exist. For instance, previous studies have revealed that there are only a handful of research studies that have addressed teen skill development and consumer confidence in the virtual marketplace (Hill \& Beatty, 2011).

Given ICTs proliferation increasing daily, we found that there are very few studies focused on older adult's ICT skills development and confidence levels, particularly those focused on ethnic minority older adults. This is a critical matter to consider given ageing workforces are diverse and increasing in all corners of life in the present times. To address this matter, we adopted a reflective stance of the digital divide with regard to older adults, where we sought to centrally position an individual rather than the technology when considering use. Therefore, we posited that technology needs to primarily provide value to the older adult and that older adults have an equal right to consciously use the technology. As such, we focus on older adults' development and confidence levels, by understanding individuals wishing to use IT but who are excluded from it for some reason; eg. a health condition that could limit their lifestyle. Given limited studies of ethnic minority older adults and older adults digital divide studies, this study aimed: To explore and understand the digital divide in older adults when accepting and using smart devices. By doing, we intend to provide older adults with opportunities of identifying the benefits technology can offer for their own personal realities. For our understanding, we drew on Wei et al.'s (2011) digital divide conceptual framework and designed training sessions based on technology-mediated learning (TML), with the objective to allow older adults to build their self-efficacy and increase their confidence levels for using IT; namely smart devices. This, in turn should lead to a reduction in the digital divide. For this purpose, we focused specifically on a group of educated Indian older adult volunteers, who have ailments, and despite their conditions expressed an interest in learning how to use advanced, novel ICTs devices.

There are two main contributions from our study. First, our findings enrich the digital divide literature by considering how the sociomaterial nature of smart devices can maximise the benefits attained by older adults themselves. Our literature reviews have shown that there are minimal studies considering the training of older adults to use smart technologies. Second, academic studies emphasising ethnic minority older adults' adoption and use of smart devices are rare as we found that within the ethnic minority culture, admission of such a weakness is not easily identified, admitted and resolved. Therefore, this study offers such novel contributions. For policy makers and technology designers, our findings challenge dominant perceptions with regard to ageing. Our findings show that older adults can be very active in their everyday, that many of them do know how to use IT and actually use it for their own personal purposes, and that some simply do not wish to, nor need to use IT at all because they have functioning workarounds to achieve what they want. As such, ICT skills programs need, first, to be focused around the diverse lifestyles of older adults, and, second, customised to their own interests with the aim to address real rather than perceived needs. Previous findings revealed that early-life education is important for later-life computer and Internet use; thereby being an important factor for digital exclusion and the "digital divide" (Kampfen \& Maurer, 2018). The study also showed that higher levels of ICT use, and perhaps technology adoption more broadly, represent a potential additional nonpecuniary long-term benefit of education (ibid). Some of these effects appear to be possible through individuals' work environments, which further suggests an important role of work and on-the-job training for life-long learning (MacArthur Foundation, 2012). Our study showed that on the job training, which our TML provided led to a benefit in the form of increased ICTs use within the volunteering older adults and an unanticipated non-pecuniary long-term benefit of education.

In what follows, we first discuss the relevant literature to contextualise our study, and then we present our research design. A presentation of our findings and their subsequent analysis is offered thereafter. Next, we discuss our findings in relation to existing literature that is followed finally by a presentation of the study's contributions and conclusions.

\section{Background Literature}

\subsection{The Digital Divide and Older Adults}

The existing differences in the ways that individuals use and accept their ICT and innovative technologies are associated with characterizations termed as 'the digital divide' (Tsatsou, 2011). Differences between users can be associated with the digital divide that has been conceptualized as operating in three levels, namely: (1) The global divide refers to the divergence of internet access between industrialized and developing countries; (2) The social divide concerns the gap between information rich and information poor in each nation; and (3) The democratic divide signifies the difference between those who do, and those who do not, use the panoply of digital resources to engage, mobilise, and participate in public life (Norris, 2001). A basic strategy for overcoming the digital divide has been to provide physical access to computers; but, as Warschauer (2004) clarifies there are three further aspects to be considered with regard to resources, which are: digital resources (material made available online); human resources (in particular literacy and education) and social 
resources (the community, institutional and societal structures that support access to IT).

The term 'digital divide' is understood in various ways, but primarily denotes the discrepancy between those who "have" and those who "do not" have access to ICTs. Typically, the digital divide discourse draws attention to individuals from ethnic minorities, from lower income backgrounds and other marginalised individuals (Cruz-Jesus et al., 2012), and their differential access to digital goods and capabilities (Kauffman \& Techatassanasoontorn, 2005; Van Dijk \& Hacker, 2003). Such differences lead to ICT-challenged demographic groups being further disadvantaged (Avgerou \& Madon, 2005; Ching et al., 2005; Dewan \& Riggins, 2005).

The digital divide has been found to be essential for social inclusion where the internet has been found to be useful for making large decisions or make their way using the internet when managing major episodes in their past years (Horrigan $\&$ Rainie, 2006). When considering social inclusion, the concept of social exclusion also arises. Social exclusion is a policy concept term that emerged in France in the 1970s and defined as: "social categories of people who were unprotected under the government's social insurance system (de Haan, 1999; de Haan, 2001; Silver, 1994). From the time it was introduced, the term has undergone changes in understanding and interpretation. In the 1980s Mitterrand's socialist government in France transformed into a new model of anti-exclusion social policies and ever since then, the term has been used in diverse contents in the UK and EU (Notley \& Foth, 2008). When considering the policy facets of social exclusion/inclusion, views are that it refers to the debate about what it means to be excluded from society and how different political and social structures should address this in a consistent way. This is then associated with Sen's (2000) development concepts where the context-specific analysis is used to understand the 'root causes of deprivation'. Research has suggested that if the digital inclusion aspect is considered, then the digital divide moves from a singular focus on technology access and towards a focus on the way technology access and use can impact different forms of deprivation and disadvantage (Warschauer 2003a, b).

In business and consumer research, social exclusion has been explained in several ways (Atkinson, 1998): (1) multiple deprivation, which is more than being financially poor or unemployed and includes not having a community or the ability to interact socially; (2) relativity which is people excluded from society at a specific place and time; (3) agency: where people or agents experience either voluntary or involuntary exclusion; and (4) dynamics: where people could become unemployed, experience financial pressure, or have fewer opportunities to prosper in the future. Burchardt et al. (1999) extended this explanation to define social exclusion as: "an individual is socially-excluded if (a) he or she is geographically resident in a society, (b) he or she cannot participate in the normal activities of citizens in that society, and (c) he or she would like to participate but is prevented from doing so by factors beyond his or her control.

Conceptually, the digital divide field has been advanced to having three levels with additive impact as shown in Fig. 1 (Dewan \& Riggins, 2005; Wei et al., 2011). The first level investigates the digital access divide and the adoption process by: seeking to explain the stages of access to IT, to support use capability and achieve outcomes. This refers to the inequality of access to IT (Dewan \& Riggins, 2005), where mobile devices are expensive, or not used due to an unavailability of an internet connection. The second level refers to the digital capability divide, i.e., the inequality of IT abilities and is seen as one of the most important aspects of inequality, focusing on the differences across groups in computer skills levels (Dewan \& Riggins, 2005). The digital capability divide further exacerbates inequality of access to IT, reflecting the importance of digital skills to access information (OECD 2007). The third level is that of digital outcome divide, which underlines the importance of outcomes stemming from the use of IT and IT investments (Wei et al., 2011). Some examples include differences in learning outcomes and productivity, examining broadband access (e.g., OECD 2007), and IT adoption in organizations (e.g., Choudrie and Zamani, 2016), and the IT productivity paradox (e.g., Ross and Ernstberger, 2006).

Focusing specifically on the demographic of older adults, they are an extremely diverse group varying considerably in their abilities, skills and experiences, which makes it particularly challenging to generalise on their needs and life conditions (Östlund et al., 2015). With respect to technology, not all older adults have adopted innovative ICTs, such as smart devices. This gap on the one hand drives the digital divide, but on the other hand, it may limit older adults' opportunities for enablement, new experiences and learning opportunities (Choudrie et al., 2018; Peine et al., 2015). On many occasions, despite popular beliefs older adults are willing and able to use technology. However, due to previous experiences, a perceived lack of support and perceived low usefulness of technology, they may experience high levels of discomfort and reduce confidence, which ultimately inhibits the adoption of the technology (Selwyn et al., 2003). Against this background, we note that the digital divide widens further as older adults typically acquire new skills slower than younger adults, which leads to them not reaching the same levels of performance, which may dishearten them and discourage them from using the newly acquired skills (Rogers et al., 1994). Finally, older adults might not be motivated to buy a computer or to learn new skills, even if they could, as they do not perceive the expected result as desirable or helpful in fulfilling their aspirations (Melenhorst \& Bouwhuis, 2004). The lack of perceived benefit and not the perception of cost seemed to have led to their negative opinions of new technologies (Melenhorst et al., 2006). This is related to the issue of 


\begin{tabular}{|l|l|l|l|l|l|}
\hline & \multicolumn{5}{|c|}{ IT Adoption Stages } \\
\hline Individual & Digital & Digital \\
Organizational & Access & Capability & \\
Global & Divide & & Divide & Outcome \\
Divide
\end{tabular}

Fig. 1 The digital divide framework. Source: Wei et al. (2011)

longevity where 'Reflexive longevity' refers to an emergent form of life, a mode of knowledge, reasoning and embodiment that older persons and their families arrive at with the aid of ethics, ageing, clinic technologies and life issues (Kaufman, 2010).

For older ethnic minority adults' research has found that the digital divide is even wider. One leading reason could be due to older migrant groups having little interest in learning how to use ICTs (Goodall et al., 2010). However, Alam and Imran (2015) found an added reason being the limited choices and the skills to use the internet (Alam \& Imran, 2015). Indeed, for these older adults it is important to have opportunities to learn how to use the novel technologies, which is central for addressing the digital divide (Benitez, 2006).

From our review of the digital divide, older adults, learning theories and the digital divide, ethnic minority older adults and learning theories it was found that there are few to minimal studies with such content. From further literature review searches, it was found that there are studies of older adults, smart devices and learning where the focus was varied; for example, studies emphasised the design features of devices for older adults (Wang et al., 2019), the use of a case study method to understand the acceptance of smart watch and bracelet adoption among the elderly for the elderly (Yu-Huei et al., 2019) and used contextual inquiry in an 18 months study of two computer rooms located in a senior residential facility. The data was collected using semi-structured interviews with 28 older adults (aged $80+$ ) that obtained the experiences of older adults' around adoption and usage of smart mobile devices, the challenges presented by these devices as a platform for communication, and the nuances of maintaining these devices over time in the context of late-life disability (Piper et al., 2016). This offered a further motivation to conduct research on how to get older adults to utilise mobile devices by focusing on their learning and training, a unique dimension to digital divide and usage studies.

\subsection{Social Cognitive Theory and Self-Efficacy}

Many digital divide studies draw from Bandura's (1977) Social Cognitive Theory (SCT) (Wei et al., 2011). In this study, we build on SCT, to investigate the role of Self-
Efficacy towards bridging the digital divide that impacts older adults and their use of smart devices. SCT incorporates the factors of self-efficacy and technology integration selfefficacy for the study of individual behaviour (Niehaves \& Plattfaut, 2014). The theory suggests that personal factors (e.g., cognition, affect and biological events), behaviour and environmental factors influence one another (Bandura, 1986), and posits that self-efficacy, or the perceived confidence for performing a task, influences the extent to which one attains a desired standard of task performance (Bandura, 1977). For example, the more supportive the feedback a person receives about accomplishing a task, the more that person is motivated to complete the task successfully (Bandura \& Cervone, 1986). Bandura and Cervone (1986) found that the use of feedback that addresses the differential between a person's performance and that of a standard or aspiration is an effective means of modifying perceptions and attitudes.

Within the context of our study, we consider the personal factors of older adults such as, age and older adults' internet self-efficacy. Behaviour refers to older adults' use of smart devices and online services, and the environmental factors refer to the provision of internet infrastructure, including smart devices and the internet. The interaction of environmental and personal factors may result in four sources of influence: vicarious experiences (observing successful task performance); enactive mastery (actual success in task performance); verbal persuasion (expressing confidence in one's successful task performance); and emotional arousal (reduction in feelings of tension or agitation during task performance) (Wei et al., 2011). These in turn shape self-efficacy (Bandura, 1986, 1989). Through enactive mastery experience, self-efficacy is achieved by practicing knowledge and skills and feedback (Kuo, 2018). Verbal persuasion refers to the available help and encouragement when difficulties are encountered, and vicarious experiences to information on others' use of ICTs, such as the internet, for task completion. Emotional arousal denotes one's confidence level when using ICTs (Joyce \& Kirakowski, 2014).

Previous research has found that older adults with less computer experience may benefit from a goal-oriented training approach, which suggests that past experiences and training intervention are equally important (Fisk et al., 2004). 
Similarly, physiological and emotional states, such as fatigue, poor memory, and joyfulness, further influence one's self-efficacy. For example, it has been shown that older adults' aging conditions, such as slow reaction, poor memory, and deteriorating vision, impact self-efficacy, which usually pertains to internet use (e.g., Caggiano et al., 2006; Whitbourne, 2001). At the same time, self-efficacy may be enhanced by modelling the performance of similar others. Vicarious experiences and social persuasion are important sources of self-efficacy beliefs of middle aged and older adults regarding technology (Lin et al., 2013). Verbal and social persuasive communication and feedback from peers and experts also influence one's self-efficacy (Agarwal et al., 2009; Bong \& Skaalvik, 2003).

In this study, we propose that to reduce the digital divide, technology-mediated learning can support older adults by building their self-efficacy towards using smart devices. Technology-mediated learning is discussed in the next section.

\subsection{Technology Mediated Learning for ICTs Adoption}

As Smart devices are the focus of this research, the study considered learning theories and models that are technology related, which led to the consideration of Technology Mediated Learning (TML). TML is defined as "[a]n environment in which the learner's interactions with learning materials, peers, and/or instructor are mediated through advanced information technology" (Alavi \& Leidner, 2001, p.2). Today, TML can be offered using smart devices, further supporting more social forms of learning (Suopajärvi, 2015; Weber et al., 2015). TML is growing in popularity as a training method thanks to its benefits, which include increased control by the learner, and cost effectiveness (Selwyn et al., 2006). Particularly for older adults there has been an improvement in technology-based tasks performance (Zulkifli et al., 2015).

Practically, TML is a blended approach that incorporates different learning methods. This blended approach often includes web and computer-based approaches, synchronous and asynchronous sessions, instructor-led sessions and self-paced sessions, and individual and team-based learning. In all cases, the learning outcomes need to be clearly established beforehand, so that these can be achieved through the chosen learning model theory (details in Table 1) and clear guidelines (Leidner \& Jarvenpaa, 1995).

When considering the suitability of learning theories, the first one of consideration was behavioural modelling where the learning is instructor-led provided and seeks to transfer knowledge from the instructor to the learner. It has been shown to be critical for training and especially for novice trainees (Kirschner et al., 2006; Mayer, 2004). Behavioural modelling suggests that learners can learn better and faster as learners see how they work. It also entails show students the standard behaviour for achieving certain outcomes. As learners begin building their expertise, the instructions need to be adapted to avoid unnecessary guidance and redundant information (Renkl \& Atkinson, 2003). Within the context of IS and ICTs, behavioural modelling suggests that learners observe instructors as they demonstrate the steps for using a computer software (Gupta \& Bostrom, 2009; Johnson \& Marakas, 2000) and has been effective for raising computer self-efficacy (Niehaves \& Plattfaut, 2014). As we were attempting to increase our learner's confidence (ie. self-efficacy), we considered behavioural modelling. Since we were invited to train, an element of instruction was required, which further prompted this team to employ behavioural modelling.

The next theory to be considered was Constructivist learning, which entails learning being controlled by the learner, and each learner creating their own knowledge according to their own pace (Leidner \& Jarvenpaa, 1995). As a result, each learner learns something slightly different, considering the influence of their past experiences, biases and abilities. In addition, constructivist learning suggests that learners learn better, because they are required to discover things on their own (they are not told nor instructed) (Leidner \& Jarvenpaa, 1995). For this study, this was suitable because it was recognised that the learners are older adults and have other technology experiences that would allow and encourage them to try out the new devices; thus, utilising constructivist learning.

The third learning theory was Collaborative learning. As a learning model, it builds on the learners' interactions (Slavin, 1990). During this process, learning surfaces as learners exercise and verify their understanding, and then solidify and improve their knowledge. Through collaboration, different perceptions and understandings become shared across the group and further refined (Whipple, 1987), and the instructor's role involves facilitating knowledge exchange and feedback provision. From the instructor's previous experiences of teaching and learning it was known that collaborative learning was needed as learners have to be offered some boundaries of freedom on the new devices use. From these experiences, questions, or issues emerge, which with the instructor being in the same location can explain and discuss, which promoted further consideration of collaborative learning. Further details of the theories are shown in Table 1.

From the digital divide, learning and smart devices existing literature it was learnt that studies of older adults' training on the use of smart devices is minimal. Further, as TML involves a blended approach, all three of the learning theories were utilised that allowed this research team to explore the applicability of all three learning models within the context of TML and the digital divide. In what follows, we discuss in detail our research approach. 
Table 1 Explanations of learning models. Source: Adapted from Leidner and Jarvenpaa (1995)

\begin{tabular}{ll}
\hline Method & Definition \\
\hline Behavioural Modelling or & $\begin{array}{c}\text { Traditional model of leaming. The goal of teaching is to facilitate the transfer of } \\
\text { Objectivism } \\
\text { knowledge from the expert to the learner. Errors in understanding are the result } \\
\text { of imperfect or incomplete knowledge transfer. Leaming is a change in the } \\
\text { behavioral disposition of an organism (Jonassen, 1993) that can be shaped by } \\
\text { selective reinforcement. The goal of teaching is to efficiently transmit } \\
\text { knowledge from the expert to the learner. Instructors structure reality into } \\
\text { abstract or generalized representations that can be transferred and then recalled } \\
\text { by students (Yarusso, 1992). The instructor is the source of objective knowl- } \\
\text { edge that is related, rather than created, during class. The instructor is in } \\
\text { control of the material and pace of leaming. The instructor assesses whether } \\
\text { transfer occurred using questions. } \\
\text { Learning emerges with the interaction of individuals with other individuals } \\
\text { (Slavin, 1990). Learning occurs as individuals exercise, verify, solidify, and } \\
\text { improve their mental models through discussion and information sharing. The } \\
\text { contribution of different understandings leads to a new, shared knowledge } \\
\text { (Whipple, 1987). The instructor's role is to facilitate maximal information and } \\
\text { knowledge sharing among leamers rather than controlling the content and } \\
\text { delivery of learning. The instructor's role is to provide feedback during class } \\
\text { although feedback from the learner's peers is similarly critical. } \\
\text { Knowledge is created, or constructed by each learner (Leidner \& Jarvenpaa, } \\
\text { 1995). The mind is not a tool for reproducing the external reality, but rather the } \\
\text { mind produces its own, unique conception of events (Jonassen, 1993). Each } \\
\text { reality is somewhat different, based on leamers' experiences and biases. } \\
\text { Instructions are controlled by learners where individuals are assumed to learn } \\
\text { better when they are forced to discover things themselves rather than when } \\
\text { they are told or instructed. Students must control the pace of instruction. }\end{array}$ \\
Constructivist Learning &
\end{tabular}

\section{Research Approach}

In this study, our aim was to support ethnic minority older adults to build their self-efficacy and confidence levels. We specifically focused on incorporating TML into our study in order to first, offer ethnic minority older adults the necessary opportunities to learn how to use the smart devices, and second, to allow them through these learning opportunities to evaluate for themselves whether technology and smart devices have a place in their own personal lives and offer value to their remaining lives. Therefore, the research methodology for this study firstly involved secondary data collection and analyses of government, industry and academic studies that led to identifying the theories and conceptual framework of this study. Then, a qualitative approach that involved collecting data based on words (Miles \& Huberman, 2009) used primary data from participants representing the various older adults age ranges; thereby offering the opportunity to thoroughly understand and analyse their respective views, a strategy like Dacko and Spalteholz (2014). Dacko and Spalteholz (2014) identified that the selected set of respondents does not have to be entirely representative at the exploratory stage of research as the focus lies on gaining diverse, detailed insights rather than predictability (Gordon \& Langmaid, 1988).

The qualitative approach was also used to reveal the meaning of actions or outcomes that can be typically measured by quantitative research in the future. Further, the qualitative approach adopted the interpretive approach that embraced Walsham's view that "our theories concerning reality are making sense of the world and shared meanings are a form of intersubjectivity rather than objectivity" (Walsham, 2006). In other words, our underlying epistemological beliefs are that knowledge can be best achieved by getting into the world of those generating it (Orlikowski \& Baroudi, 1991). A key advantage of interpretivism is that equivocal outcomes of IT adoption are potentially accounted for by understanding how the social meanings attached to the technology originate and evolve. Therefore, this approach allows us to consider both the influence of the implemented technology and the broader context. Thus, by using interpretivism on the one hand, we can understand how older adults perceive their self-efficacy with IT and smart devices and comparatively, the influence of these devices within a broader context (Orlikowski \& Baroudi, 1991; Walsham, 1995). According to Kumar et al. (2002) qualitative research enables detailed insight and an understanding of context. As such, the methodology supports the research focus on understanding, not measuring (Gordon \& Langmaid, 1988; p. 1).

It should be noted that the application and examination of the tablet devices occurred based on Orlikowski's (2000) conceptualisation of the IT artefact, which is: A technological artefact is a bundle of material and symbol properties packaged in some socially recognizable form, e.g., hardware, software. In the same way, we suggest that tablet devices are not 
only application devices that are provided using hardware and applications, and content to organizations. Tablet devices with their smart features offer organizational characteristics such as, task variety, executive support, and provide personal content where user participation shapes the outcomes of their use. We also built on an interpretive in-depth case study, where we focused on the tablet as the focal IT artefact that is used for facilitating training and can be used for work and personal purposes in a marginalized societal group (i.e., Indian older adults).

Our in-depth case study took place over a six months period in Southall, London (UK). Southall has a population of about 65,000 , with $83 \%$ of the residents being of ethnic minorities, namely $63 \%$ Asian and $47 \%$ Indian. It is noted that currently, Southall hosts the largest Sikh (North Indian) community (Hiddenlondon, 2018). In addition, it is home to numerous multicultural organisation and charities, including culture-specific local radio stations.

As we were interested in investigating if and how TML can help older adults in building their self-efficacy and confidence towards using smart devices so that the digital divide can be reduced, our study required that we identified a group of older adults, with an interest in learning how to use such devices. At this point, we identified a Punjabi radio station that is operated entirely by volunteers and whose Chairperson was interested in offering its staff members IT-related learning opportunities, which was also viewed to be on-the job training. However, ultimately, the participants selection was based on those who were volunteers in the organization, contributed to the daily operations of the radio station and were internet users. They were not necessarily decision makers in the organization as this was not the aim of this study. The volunteers themselves were all first-generation migrant Indian older adults, who were settled in the UK and of various ages, which reflects the diversity of the age ranges of older adults.

Indian older adults are very social, but less well versed in the use of new technologies, and internet browsing, and mostly prefer face to face interactions or the classic channel of landline telephony instead of mobile phones. The group of educated, volunteering older adults exhibited an interest in learning how to use the internet and determining how technology can potentially help them in their everyday life. As a result, the group of participants allowed us to investigate how TML can potentially support them in getting familiar with smart devices, and in doing so, increase their confidence and self-efficacy. The participants of this study numbers were selected on the basis of data saturation, which is used for qualitative studies. Data saturation for this study was a combination of when 'the researcher begins to hear the same comments again and again; data saturation is being reached... It is then time to stop collecting information and to start analysing what has been collected' (Grady, 1998; 26); 'the point in coding when you find that no new codes occur in the data. There are mounting instances of the same codes, but no new ones' (Urquhart, 2013: 194); the point at which 'additional data do not lead to any new emergent themes' (Given, 2016; 135). To further confirm the suitability of the numbers of participants, previous scholars such as Adler and Adler (2012), Becker (2012) and Saunders (2012) were referred to, where based on their previous experiences, 12 participants were viewed to be enough for qualitative studies. Table 2 presents the details of our study's participants.

All the participants were English and Punjabi (North Indian language) speakers. Overall, there were 12 participants in this study: 10 females and 2 males, of which 2 are pre-seniors, 6 are young-olds and 4 are old-olds. Seven of the participants had some type of ailment; i.e., heart disease (1); visual impairments (1); ear disorders (1); memory problems (2); arthritis (4); thyroid (2). This suggests that while our participants can be classified in the different age groups as described in the literature (Whitford, 1998), their profile is even more nuanced because their health condition allows and prohibits different lifestyles concurrently. We used the various segments to understand older adults because adults are ageing and living longer, where it has been found that there is no longer a single stage to understand the term 'old'. Therefore, this led to different segments for understanding different older individuals' needs and interests (Greenberg, 2009). Most of the participants were educated in India except for one individual who had a postgraduate qualification from the UK. There were three participants with an undergraduate qualification and the remaining eight were educated to high school levels (A levels) or holders of vocational qualifications. For family arrangements, the Indian culture of extended families was prevalent, where seven out of the twelve participants were grandparents and lived in intergenerational households (children and grandchildren). In terms of internet experience, two of the old-old adults were intermediate users as they used the internet for limited purposes, such as email and seeking support from family or trusted colleagues when pursuing new tasks and skills but are quite experienced in smartphone use. The three housewives from the young-old and one from the old-old category had no internet experience, used basic mobile phones, but were very keen to pick up new internet skills; thus, viewed as novice users. The rest were quite experienced with the internet as well as tablet devices and categorised as advanced users.

To create an environment for examining TML, we designed and delivered training sessions to our participants. These training sessions were designed around use scenarios in order to make training more attractive by being tailored to their own specific needs. Consulting with the station's Chairperson, education and age emerged as critical aspects that required additional consideration for the delivery of the sessions: 
Table 2 Details of the study's participants

\begin{tabular}{|c|c|c|c|c|c|c|c|}
\hline Code & Age & Gender & Numbers & $\begin{array}{l}\text { Category } \\
\text { of Older } \\
\text { adults* }\end{array}$ & Occupation & Education & Ailment \\
\hline i1 & $50-64$ & Male & 1 & Pre-senior & Lecturer & $\mathrm{BA}$ & $\begin{array}{l}\text { Heart problem and } \\
\text { high blood } \\
\text { pressure. Had a } \\
\text { by-pass. }\end{array}$ \\
\hline i5 & & Female & 1 & Pre-senior & Entrepreneur & A levels & Healthy \\
\hline N/A & $65-74$ & Male & 0 & Young-old & N/A & & N/A \\
\hline i3 & & Female & 6 & Young-old & Teacher & $\mathrm{BA}$ & Healthy \\
\hline i6 & & & & & Housewife & A levels & Healthy \\
\hline \multirow[t]{2}{*}{ i10 } & & & & & Housewife & A levels & Healthy \\
\hline & & & & & Housewife & A levels & $\begin{array}{c}\text { Rheumatoid Arthritis, } \\
\text { Slow Thyroid }\end{array}$ \\
\hline i8 & & & & & Craftsperson & A levels & $\begin{array}{l}\text { Slow thyroid, } \\
\text { mobility }\end{array}$ \\
\hline i7 & & & & & Public sector & A levels & Mobility, Osteo \\
\hline i11 & & & & & $\begin{array}{l}\text { administra- } \\
\text { tion }\end{array}$ & & Arthritis, Memory \\
\hline i4 & $75-85$ & Male & 1 & Old-old & Engineer & $\begin{array}{l}\text { City \& } \\
\quad \text { Guilds }\end{array}$ & $\begin{array}{l}\text { Slow walking } \\
\text { (mobility) }\end{array}$ \\
\hline i2 & & Female & 3 & Old-old & $\begin{array}{l}\text { Radio } \\
\text { chairperson } \\
\text { and teacher }\end{array}$ & MA & $\begin{array}{l}\text { Memory, arthritis, } \\
\text { visionary } \\
\text { impairment, } \\
\text { vertigo, Tinnitus } \\
\text { (Ear problem) }\end{array}$ \\
\hline i9 & & & & & Craftsperson & A levels & $\begin{array}{c}\text { Rheumatoid Arthritis, } \\
\text { Obesity, Diabetes }\end{array}$ \\
\hline \multirow[t]{2}{*}{ i12 } & & & & & Housewife & $\mathrm{BA}$ & Healthy \\
\hline & Total & & 12 & & & & \\
\hline
\end{tabular}

*the categorisation of older adults follows the classification of Whitford (1998)
"Some of our people have studied here in England, but some in India, so you cannot use only UK based content. Also, you teach university students. Not all our people here have been to university, so do think about what you will provide." (i2)

As a result, we decided to create content, specifically designed for this age group, in collaboration with students from a local University. Over a period of six months, we organised and delivered 13 TML training sessions in the radio station's premises and outside our participants' working hours. The first two sessions were aimed at identifying what challenges older adults typically faced when using the tablet and involved primarily instructor-led discussions. For example, internet security was something we touched upon early on during our first session, and the participants were asked by the instructor how they managed their internet security. It was then that use, and self-efficacy issues began emerging as important concepts. This helped us sharpen our understanding with regard to the needs of our Indian older adults and showed us that despite that all of them having access to a tablet, not all of them were familiar with its basic features. Another example involved seeking the participants to identify websites, features of importance such as, the magnifying glass (search feature), how to delete and increase the numbers of tabs. What was noted is that we had to simplify terms to the levels that older adults understood. The previous example of the search feature is one such example. As a result, each subsequent session was designed in a reflective manner, drawing on discussions and observations during previous sessions. For example, we delivered a session on the features and functions of the tablet, a session on using online social networks and applications and their usefulness, and finally a session on cybersecurity.

Overall, 13 sessions were designed and delivered in a way to reflect the types of skills that older adults need to use internet-based devices and the teaching and learning requirements they have. This included considering issues such as, allowing enough time to process events and information, and pauses between instructions and execution to allow time for questions (Jones \& Bayen, 1998). The first 12 sessions lasted approximately two hours and took place on a one-toone basis. These sessions were designed around the principles 
of behavioural modelling. The first half entailed practicing the tasks shown during the previous session, and the presentation of new tasks. The second half involved face-to-face semistructured interview discussions regarding the participant's confidence levels in undertaking the said tasks, as well as identifying tasks for the subsequent sessions. The final (13th) session lasted approximately one hour and was designed around collaborative learning involving all the participants. The participants were provided with a multiple-choice questionnaire, which was used to ascertain their newly acquired knowledge and verified and validated (i.e., triangulated) our findings and understanding. The questionnaire involved asking questions based on the activities that they were taught with and the training team observing them.

The first author was the principal investigator and served as the insider to the organization. Being of Punjabi descent and very well known to the radio station, where she volunteers, she was deeply immersed and familiar with the environment, which provided us with intimate knowledge regarding the culture and the perspectives of the participants. The remaining authors performed the 'devil's advocate' role where they requested theoretical justification of the practices under investigation (Eisenhardt, 1989), and interpreted the findings considering their knowledge and expertise in the areas of digital divide and self-efficacy.

\subsection{Data Collection and Analysis}

Data collection involved using unstructured and semi structured face to face interviews, and observations. There were also approximately 10 informal chats ranging from between 15 and 30 min held with the participants on different occasions to the training days, a strategy like Zuboff (1988). This was during teatime when the principal investigator was invited to the radio station. The 36 interviews questions focused on the experiences and understanding of using the tablet, the Internet, the social interactions with significant others (relatives, peers etc.) and reactions to problems encountered. In addition, older adults were asked about how and what their understanding changed with regard to their level of confidence during the 6 months period. All the activities and informal conversations were recorded and later transcribed. In conjunction, we were preparing analytical memos, which were similarly analysed. Our preliminary observations and interpretations were shared with the participants for clarifications and verification; thereby ensuring triangulation.

The data was analysed using a deductive approach based on grounded theory method techniques (Glaser \& Strauss, 1967). We chose this approach because it is a systematic and robust approach, without restricting the researcher into preconceived codes and categories, while supporting the development of relationships between them (Urquhart, 2012). This allowed the emergence of newly identified concepts, while remaining informed by the existing literature. It also allowed analysis of our material without superimposing necessarily previous conceptualizations of the examined themes nor our presumptions on to the coding scheme. A summary of our approach is shown in Table 3.

While coding our material, we followed a bottom-up approach, with the aim to assess the influence of TML on older adults' self-efficacy to use smart devices. The coding scheme we derived builds on the digital divide, selfefficacy and TML literatures. We began open coding by analysing our data line-by-line and identifying as many codes as possible. Emergent concepts were placed into newly created codes and were later re-examined considering the evolving coding scheme. Open codes were then grouped together with the resulting groups being each other's variants, and properties (selective coding). From selective coding we abstracted to theoretical coding, identifying our study's core categories (Urquhart, 2012), namely self-efficacy, vicarious experiences, enactive mastery, verbal persuasion and emotional arousal. Table 4 presents an example of our interpretation process. 'First-order data' refers to our participants' constructions, 'key idea' refers to the quotation's essential meaning, and 'second-order concepts' presents our constructions (Walsham, 1995). Finally, while developing our study's chains of evidence, the analysis began by revealing the relationships among the various core categories.

\section{Findings and Analysis}

In this study, we investigated how to train older adults to use smart devices in order to reduce the digital divide. For this purpose, we used TML as an example of a present intervention offered in a workplace for workplace training to support the reduction of any existing digital divide. With TML, a combination of the learning theories leads to good results, which led to the application of all three classic learning theories. The tablet was used as an example of a smart device. The training sessions were designed with the aim of helping older adults to learn how to use the device, and at the same time, employ TML to help them learn how to use the internet and other applications.

As the focus of our aim is on the digital divide, for our finding's analysis, we adopted the three-level digital divide framework of Fig. 1 (Wei et al., 2011) where the first level refers to the internet infrastructure provision, which was essential to our study. The second level refers to personal IT abilities and the capability development nature of the training sessions, and the third level, refers to the outcomes achieved from these sessions, using specifically self-efficacy, knowledge and skills outcomes (Wei et al., 2011). These are discussed in the following sections. 
Table 3 Stages of data collection and analysis

\begin{tabular}{|c|c|}
\hline Stage & Description of the Process \\
\hline \multirow[t]{2}{*}{ 1. Design of training sessions } & $\begin{array}{l}12 \text { training sessions were designed on a one to one basis. This was around } \\
\text { themes such as internet security, uses of tablets, features and functions of } \\
\text { tablets, and cloud-based application. }\end{array}$ \\
\hline & $\begin{array}{l}1 \text { training session (13th session) was designed around collaborative learning } \\
\text { and with the aim to assess the newly acquired IT skills. }\end{array}$ \\
\hline 2. Familiarisation & $\begin{array}{l}\text { Review of the empirical material - reading and rereading the collected data } \\
\text { from the interviews, and our observations. }\end{array}$ \\
\hline \multirow[t]{3}{*}{$\begin{array}{l}\text { 3. Identification and review of } \\
\text { codes and themes }\end{array}$} & $\begin{array}{l}\text { Open coding: analysis of material line-by-line, and coding around known } \\
\text { and newly emerging concepts. }\end{array}$ \\
\hline & $\begin{array}{l}\text { Selective coding: grouping of open codes, identifying variants and } \\
\text { dimensions of codes. }\end{array}$ \\
\hline & $\begin{array}{l}\text { Theoretical Coding: abstraction from selective codes identifying core } \\
\text { categories (self-efficacy, vicarious experiences, enactive mastery, verbal } \\
\text { persuasion and emotional arousal) }\end{array}$ \\
\hline 4. Review of codes and themes & $\begin{array}{l}\text { Two of the authors reviewed the codes and themes, ensuring that each } \\
\text { reflects the topic of the study, and that they are exhaustive and mutually } \\
\text { exclusive. }\end{array}$ \\
\hline 5. Reporting Findings & $\begin{array}{l}\text { Selection of quotes, development of chains of evidence, revisiting the } \\
\text { literature and developing findings. }\end{array}$ \\
\hline
\end{tabular}

Stages 3 and 4 were iterative in order to review the evolving coding scheme

\subsection{Digital Access Divide}

For the purposes of our study, internet availability is integral as smart devices require internet access to provide content, initiate actions, and respond to stimuli. During our first visit at the radio station, the team informed us that internet access was not available throughout the premises. Specifically, the space where all the training was meant to be carried out did not have internet access. Further discussions and observations revealed that this was due to the affiliated costs and preferences with respect to interpersonal communications:

"We are a charity and do not have too much money. We do not need the internet here because this is more of our talking with one another place and we do not want to take away from that concept. It is also a waste of money because we do not use the technology here. If you do want to use or show how to use the internet, then find a way from your IT knowledge. We have the internet in the next building where the studio is located" (i2)

As we were specifically interested in providing training and to overcome this obstacle, we sought tablet devices that offer anytime, anywhere access and can be used for personal and work purposes. For internet access, a Mi-Fi (mobile Wi-fi) device with a broadband connection of 50 Mbps was used.

To ensure that the older adults would continue practicing the new digital skills, we asked them about internet access in their households. During the informal interview sessions, we learnt that all of them had broadband connections and smart devices (e.g., smartphones and tablets), which they paid for themselves. They considered these smart devices as devices for personal use only. With regard to, particularly the tablets they would rarely consider bringing them with them to the radio station as it was viewed to be a personal device that was meant to be used only at home or in their personal time. At work it was felt that a separate device should be provided because employers were required to provide the equipment and not the workers.

"My phone is for my use and my ipad is for home. If I need something done using the internet at work, I'll ask Penji or the manager to let me use the desktop, or their devices. I won't bring my home and personal device" (i8)

Progressively, it became apparent that the participants were keen to attend the sessions with the instructor, and excited about trying out a new smart device with the help of a qualified instructor:

"They feel very important that a Professor comes to teach them. People from universities are individuals that their grandchildren or children will have met and not them, so they are attending. As these classes are free of charge and the devices are freely used draws them to attending the classes." (i2)

"I have an ipad but it is quite old, so now I want to see and feel the difference and if it is good, I might buy a 
Table 4 Example of the interpretation process

\begin{tabular}{|c|c|c|c|}
\hline & First-order data & Key idea & $\begin{array}{l}\text { Second-order } \\
\text { concepts }\end{array}$ \\
\hline Self-Efficacy & $\begin{array}{l}\text { After the } \\
\text { demonstration, } \\
\text { we explained } \\
\text { the location of } \\
\text { a feature e.g., } \\
\text { the control } \\
\text { centre where } \\
\text { the Wi-fi set- } \\
\text { tings are, and } \\
\text { how to add } \\
\text { tabs. The par- } \\
\text { ticipants } \\
\text { turned to their } \\
\text { devices and } \\
\text { continued with } \\
\text { the activity. } \\
\text { We observed that } \\
\text { the old-old and } \\
\text { some later } \\
\text { stage young } \\
\text { old (about } \\
\text { 78 years old) } \\
\text { would seem } \\
\text { tensed and ask } \\
\text { repeated ques- } \\
\text { tions: "How } \\
\text { can we tell } \\
\text { whether we } \\
\text { have a Wi-fi } \\
\text { connection and } \\
\text { what it is" } \\
\text { (Old-old i4). } \\
\text { The younger } \\
\text { adults } \\
\text { continued with } \\
\text { the task after } \\
\text { the } \\
\text { demonstration, } \\
\text { smiling. They } \\
\text { would also } \\
\text { make } \\
\text { comments } \\
\text { such as: "This } \\
\text { isn't difficult, I } \\
\text { know where to } \\
\text { find this } \\
\text { feature. I have } \\
\text { done this } \\
\text { before." (i1) }\end{array}$ & $\begin{array}{l}\text { Self-efficacy is } \\
\text { about } \\
\text { confidence } \\
\text { levels. Even } \\
\text { though we } \\
\text { explained } \\
\text { where details } \\
\text { of the Wi-fi } \\
\text { can be found, } \\
\text { which is an es- } \\
\text { sential feature } \\
\text { of a smart } \\
\text { device, the } \\
\text { old-old needed } \\
\text { guidance, as- } \\
\text { surance and } \\
\text { additional in- } \\
\text { formation. } \\
\text { The pre-seniors } \\
\text { and young-old } \\
\text { experienced } \\
\text { vicarious ex- } \\
\text { periences and } \\
\text { enactive mas- } \\
\text { tery as they } \\
\text { observed the } \\
\text { instructor and } \\
\text { then continued } \\
\text { with the activi- } \\
\text { ty to success. }\end{array}$ & $\begin{array}{l}\text { Differences in } \\
\text { 'confidence' } \\
\text { levels of } \\
\text { individuals are } \\
\text { clearly evident } \\
\text { from the } \\
\text { replies. } \\
\text { For old-old, we } \\
\text { classified their } \\
\text { comments } \\
\text { under verbal } \\
\text { persuasion and } \\
\text { emotional } \\
\text { arousal, as they } \\
\text { needed extra } \\
\text { support and } \\
\text { encouragement } \\
\text { in order to carry } \\
\text { on and attempt } \\
\text { to complete } \\
\text { their tasks. } \\
\text { The Pre-senior } \\
\text { and young-old } \\
\text { continued with } \\
\text { the set tasks and } \\
\text { activities, and } \\
\text { we classified } \\
\text { their comments } \\
\text { as vicarious ex- } \\
\text { periences and } \\
\text { enactive mas- } \\
\text { tery (they ob- } \\
\text { served the in- } \\
\text { structor and } \\
\text { then continued } \\
\text { with the activi- } \\
\text { ty). }\end{array}$ \\
\hline
\end{tabular}

new one. However, it (i-pad) is expensive and I need to understand and know its benefits for me." (i1)

In other words, with respect to the digital access divide in the population of this study, older adults, while at home and during their volunteering at the radio station do have access to smart devices; specifically, to tablet devices. However, they don't have the opportunity to use them for a combination of reasons; eg. because their workplace doesn't offer an internet connection (ie. the radio station), or due to the group being unsure of the potential benefits stemming from using the devices in their workplace. What was discovered is that older adults separated the use of devices in terms of the context; eg. smart devices for personal use and separate technologies for work purposes. If the devices were provided by and paid for by the employers, they would then use them in both environments.

The provision of one-to-one training through TML with the support of a qualified instructor offered older adults with the opportunity to find out more about the tablet as a smart device, which meant showing them novel features and the 'nomadicity' aspect of the devices. In this respect, it echoes the importance of 'informating down' (Leidner \& Jarvenpaa, 1995), where TML-based sessions provided an opportunity for older adults to discuss tablet device use issues and obstacles faced with their instructor and with each other. This was novel and was an incentive to continue with the training for the group.

\subsection{Digital Capability Divide}

Resulting from the digital access divide as well as other contextual factors is the digital capability divide that denotes inequalities of skills for accessing and using IT (Wei et al., 2011). As such, to overcome the digital capability divide, one must ensure that there is no or very little inequality in people's ability to use IT (Dewan \& Riggins, 2005). This in turn suggests that, first, we needed identifying the pre-existing abilities of the participants to determine the gains in skills and self-efficacy (Wei et al., 2011) and the impact of our approach to TML.

To address this matter, in the first session we learnt of the participants educational backgrounds, their ICTs knowledge, work experience and their duties in the radio station. This allowed formation of the training sessions. For instance, we knew that there were many individuals who had high school level education, so we could inform individuals at a high level of understanding rather than at a very basic level. This implied that we did not need to form content restricted to only pictures and the use of pens, pencils and exercise books. We could refer to eg. the use of printers or photocopiers in individual lives. During the second session, we queried participants with regard to their ability to use key functions of their smart devices including, smart phones that were also of the same brand, had features of the tablet devices and all of them had. We asked questions such as: "Where is the power button?" and "Where in your phone do you change the setting to the airplane mode?". All the older adults showed us the power button on their device, but the old-old and two of the youngold could not clearly and confidently specify how to change 
the function to airplane mode. In addition, all of them were aware of this function, as they used it when flying out to India. What is interesting is that because all of them are iPhone users, which are also smart devices with similar attributes to the tablet devices it was easy and straightforward to explain to them that the same features and functions were applicable to the iPad tablet. In turn, they were able to apply their skills and knowledge to both devices.

Further, we worked with them to identify the search function, and helped them to understand how to add or remove tabs in their internet browser. At this point, the concept of internet self-efficacy became relevant. Also useful at this stage was the familiarity with categories of older adults and what this research team understood older adults to be. Generally, in research older individuals aged 50 years and above with the knowledge and ability of using ICTs are known as 'silver surfers' (Netlingo, 2021). To form a better understanding of aging, categories have been formed in previous older adults' studies that has led to terms for assorted older adults age groups; eg. Pre-seniors (aged 50-64 (Whitford, 1998); young-old (aged 65-74); old-old (aged 75-85). There is also the oldest-old category (85+) in older adults as well (Schaie \& Willis, 2002; Lee et al., 2013). Since there have not been many studies of older adults and smart devices and our research impinges on self-efficacy and other psychology and older adults research, we used the previous three categories to complete our study's purpose.

Emotional arousal within the old-old group was quite evident, where participants became quite stressed and anxious when asked to use the internet for performing tasks. At that point they stopped using the device and began to watch their peers. If a reason for sitting as they were was sought, the replies were usually:

"I do not know what to do, what should I do? I will do it later." (i9)

Sensing the participants' anxiety, the instructors would sit with them and show them how to address the tasks. We subscribed this to vicarious experience, where participants would observe the completion of tasks by the instructors, accompanied by verbal arousal, where the instructors would verbally encourage the participants following their emotional arousal. Following this, the participants were asked to imitate and reproduce the same results, which indirectly helped them by increasing their abilities of using the internet on a smart device.

While working on internet browsers, we observed that not all participants were aware of what an internet browser is. All of them were aware of names like Safari, Internet Explorer and Chrome, among others. However, they were unaware of the term itself. The participants mentioned that since the first time they used the internet, they have been using the name of the browser they were using. This they viewed to be a distinct application, rather than as one of the many variations of internet browsers, which resulted in the name of the internet browser imprinted in their minds. The old-old participants discussed how they grew up without internet access and how they begun and completed their professional life without having access to any internet-related products and services, which resulted in them not seeing any relevance of the internet in their lives nor trusting the technology:

"I am used to reading and writing and feel much better when I consult a dictionary or an encyclopaedia. Why do I need the internet and a tablet device when I have my trusted notebook, pen and pencil?" (i9)

Once the participants began to understand the importance and the usefulness of smart devices and their features, and began to become more confident when using them, they began using the devices more often. This was confirmed during the last session when they began tackling the set activities without receiving any instructions or other guidelines.

With respect to the other older adults' age groups, we observed quite a few differences in terms of abilities. For example, when asked to add a tab to their internet browser, the preseniors were quick to demonstrate how to complete the task. However, the young-old, and more so the old-old, could repeat the actions, but they would quickly forget the tasks' outcomes. For this reason, the members of these two groups were allowed more practice time on how to use smart devices features. By doing so, they built their confidence, although much later in comparison to the pre-seniors, who displayed enactive mastery experience within the first two weeks. However, this was the result of pre-seniors possessing more than the basic knowledge of IT and internet use. This was not entirely unexpected as participants from within this age group are recent retirees; therefore, they haven't been away from the workplace for long, and have been using IT for work purposes up until recently.

As in other studies (e.g., Wei et al., 2011), we observed a feedback loop, where the use of personal smart devices led to an increase of the participants' ability to use them. One example of this is participant $\mathrm{i} 1$, who is a pre-senior with a heart condition that prevents him from having a full-time job and is a freelance consultant for an internet training enterprise in the private sector that trains refugees. In this case, the training provided through our sessions were helping il to familiarise himself more with the internet and build his confidence, which helped him in using the internet and his smart device more and assisted him in his role as a consultant. In addition, TML through the tablet and at his own pace, helped him gain access to training and built his self-efficacy despite his healthrelated difficulties. 


\subsection{Digital Outcome Divide}

The general aim of the provided training sessions was to help older adults develop capabilities when using smart devices through our TML approach beyond the duration of these sessions. As a result, it was required that the developed capabilities would be sustained and made use of in the future; thus, overcoming the digital outcome divide.

At this stage, we queried into applications offered by the smart devices, such as email, office automation tools (e.g., Word and Excel), cloud-based tools (e.g., Dropbox and Google docs). Participants were asked whether they used any of them. If yes, how, when, where and why did they use them. The old-old participants didn't see the relevance of cloud-based tools in their lives. While they acknowledged their convenience, they discussed the nuisance of maintaining an additional account and sharing their personal details with these services:

"I have this (pointing to a USB) if I need to save something very big, otherwise, I can save it on my computer.

I don't believe in these cloud things." (i4)

As a result, the issue of personal internet security emerged as an influencing factor for this age group. Further, they commented that the required steps to access cloud-based tools seemed far too complex for them at their stage in life.

Two participants in the pre-seniors age group were using Dropbox, with one of them (i1) using it more often. He considered it as an important and relevant application for his lifestyle due to his occupation prior to retirement. Over the weeks, he revealed that he has been having private internet teaching classes with some refugee families and the training that he was receiving from us was assisting with his delivery, which suggests there was a feedback loop between the sessions he was attending and those he was delivering, which is an unexpected outcome of knowledge spill over. Further, it was observed that, when participants were asked to save some larger documents, the old-old avoided using cloud-based applications altogether. Instead they sought to use USBs and their computers. We consider this to be a familiarity issue, as the use of external devices for file storage has been available for longer, and therefore quite likely our participants could have been exposed to such IT earlier in life.

To assess the self-efficacy and confidence levels, we invited older adults to share with us their perceptions with respect to these two factors: "Has your confidence increased, or decreased as a result of the sessions, and why?", "How would you rate the change of your confidence over these weeks and why" (Lin et al., 2013). The pre-seniors and some young-old participants explained that their confidence and self-efficacy levels had improved as far as internet security, cloud-based applications and online social networks were concerned. They were also keen to apply their newly acquired skills in the future:

"I knew that there are things I can watch out for on a website. Now, after this and the notes that you gave us, I now know that I should watch out for a padlock, or the https at the start of the address" (i1)

"I know that Barclays has been showing advertisements about these things, but now with the notes, I can just refer to them and use the internet when I want." (i3)

However, the old-old participants perceived changes in confidence only in terms of internet security, which nevertheless was very relevant for their daily activities:

"I now feel that I can find out whether a website is one that I can, or not trust, which was something I did not do before. Before I would not use the internet and sought to find other ways of seeking the same information than that from a website". (i9)

"Yes, Penji ('elder sister' in Punjabi) is much better than before. Before, she would avoid the internet and have someone else handle the matter rather than herself". (i5)

The housewife from the old-old category was the only one in this category to mention using Youtube on the iPad as the screen was better and allowed her to view the videos much better. However, when using e-mail or Whatsapp she used the smartphone as she learnt how to use these applications with the smartphone and not the i-pad. What was learnt is that the iPad was associated with entertainment rather than e-mail and was used in that manner. As an example, Youtube was used to learn of new food recipes and to learn of the biographies of old, bygone days Bollywood stars. However, the recipes were not found to be of relevance or useful, so Youtube was associated with television and movies, and with the iPad offering a larger screen, it was used in a manner like television. For this user and the others who had learnt how to use the internet, and emails with the smartphone, it was associated with being largely a communication device and aligned with being an 'official' device. What was also discovered is that the housewife and other housewives would not visit friends or shopping centres and other external areas without family members, and they would not take the smartphone or i-pad anywhere with them. If they were on their own, they would use the landline, or ask their friends or relatives to make calls for them. Upon further probing it was discovered that the housewives were reliant upon their husbands for travelling and going out of the house as the Indian culture dictates, so they were still in that mode of culture where power was in the hands of males and escorted the females to places of interest.

These changes in confidence levels were the result of verbal persuasion and emotional arousal through their 
conversations with younger family members (e.g., grandchildren, children, nephews and nieces) on the topics discussed during the training sessions. The old-old participants explained that prior to the sessions, they would browse the internet through their smart device but only if their younger relatives were there. Their relatives would correct them in case of mistakes or support them if they felt less confident. However, after the training, this was no longer the case:

\begin{abstract}
"I have my niece there, but now I use the internet on my own. Only if I face a problem, does she help me, which before I used to wait for her to come to my house and she used to do all my internet related work. I can also search for information on my own and when I face a problem, I can ask others at the station and reason my actions with them. Before this was not possible. This has helped me to save time because now I can get on with my work and do not have to wait for anyone. This is certainly beneficial in this way." (i2)

"Now, I can tell my son in New Zealand about certain steps that I took when using the iPad that I could not before. Before, if he would tell me something, I listened and followed the instructions, but no longer. I am more confident with my steps and can explain matters." (i5)
\end{abstract}

Therefore, following these training sessions and using smart devices and TML, older adults' skills and capabilities increased considerably, which in turn, reduced the digital outcome divide. At the same time, some intangible benefits emerged, which included the reduced time waiting for a third party to support them in their interaction with the tablet, as well as the use of the tablet in business-related activities that leads to, in this case, an external knowledge spill over.

\section{Discussion}

Early life education is vital for the adoption of computer technology and Internet use among older adults (Kampfen \& Maurer, 2018). Previous research has revealed that highly educated workers tend to adopt new technologies faster than those with less education (Lleras-Muney \& Lichtenberg, 2002; Welch, 1970; Wozniak, 1984, 1987). In a Canadian study one additional year of education in response to new compulsory schooling laws resulted in a seven-percentage point higher probability of on-the-job computer use among Canadian employees (Riddell \& Song, 2017). However, they did not provide any evidence on digital exclusion and the "digital divide" more broadly due to their exclusive focus on employees and ICT use at the workplace, as non-employed individuals and persons who do not use computers at work may still use ICT for communication, information acquisition or online shopping in private. To overcome such a gap,
Kampfen and Maurer (2018) considered older adults use both at work and at home, thereby providing direct evidence on the role of education as an underlying factor for the "digital divide" and digital exclusion of older adults. Our study went one step further and utilised the platform of early education, which was not a selection criterion and showed how training provided in the workplace and increased use at home and at work can result in adoption of ICTs within older adults. Our study then identified the diverse older adult categories that are apparent in literature and the role of more, previous work experience and roles influencing adoption levels. For instance, our findings showed that pre-seniors and young-olds possessed more than basic knowledge in using ICTs and the internet, compared to old-olds. This is mainly because the first two age subgroups were either recent retirees or still in some type of employment, with IT and internet training being provided through their workplace. Such findings are further confirmed by previous studies (e.g., Agudo et al., 2012; Gonzalez et al., 2015; Martínez-Pecino et al., 2013) who found that age, and workplace training impact older adults use of and self-efficacy in ICTs. With regard to the old-old Indians, who were out of employment the longest, and also having a participant being highly educated, our training sessions helped them to increase their internet self-efficacy, while practising their skills during and after the sessions. Their increased self-efficacy in turn led to decreased IT-related anxiety, which negatively impacts IT use (Vroman et al., 2015). Indeed, existing research on older adults suggests that technophobia and mistrust towards technology can be addressed through similar digital skills training (e.g., Cattan et al., 2005; Hill et al., 2015; Lagana, 2008).

Participants across all three age subgroups considered the training sessions as a great opportunity for them to develop their skills. Indeed, research suggests that older adults from minorities do not necessarily refrain from using technology because they are unwilling to do so or because they don't see any value in it. Instead, belonging to an ethnic minority may restrict further one's choices and opportunities towards learning how to use ICTs (Alam \& Imran, 2015; Benitez, 2006). Both approaches to TML (collaborative learning and behavioural modelling) offered them hands on experience with the tablet, which is critical for enactive mastery experiences (Koh, 2011). Enactive mastery experiences may emerge through the completion of tasks and activities that entail the use of newly acquired IT skills, and which are along the lines of one's everyday workflows (Beyerbach et al., 2001; Pellegrino \& Altman, 1997; Snider, 2002). In our study, enactive mastery surfaced while the older adults were tackling previously prepared tasks that addressed their own interests, professional life, and themes such as the Punjabi culture. As a result, using the TML approach directly provided our participants with the much-desired learning opportunities, while at the same time illustrated practically the usefulness and the utility of the technology for their own personal life situations. 
In this respect, we highlight the importance of using relevant content and tasks for individuals' lifestyles and personal interests, so that the participants remain engaged and are best placed to identify the potential benefits smart devices for their circumstances.

With respect to the four different sources of influence on self-efficacy, we observed significant differences among participants; vicarious and enactive mastery experiences were more prevalent in the younger Indian older adults (i.e., preseniors and young-old). In contrast, the old-old seemed more sensitive to verbal persuasion and emotional arousal. While it is difficult to generalise from such a small sample, we consider that these differences may be because the younger subgroups were either still active professionally in some capacity or they had fewer years post retirement, and therefore had more recent experiences with ICTs. What was also apparent is that the older participants seemed to value personal interaction with the instructor, and emphasised support provision and building trust relationships much more than the younger adults.

Due to the basic level of offered training, the participants identified a positive impact on their everyday practices. As they became more confident in undertaking IT-related tasks, they felt able to perform better while volunteering at the radio station and being independent during their personal time, which was of distinct personal importance for them. For example, a participant (i2) highlighted that while in the past, she would consult a younger relative about the security and appropriateness of different websites, she was now confident in doing her online shopping and looking up interesting websites on her own. This has also now led to this participant using online banking, which she was fearful of and did not trust. She revealed that this has led to her saving time because she did not wait for anyone to take her to the bank or wait for a cashier to cater to her banking needs. For the organization, this meant that their online payments were expedited to previous instances when individuals had to be found to visit the bank and complete financial transactions. The organization has also now implemented an online payment system, which is leading to the organization being able to operate faster when disseminating the donation payments. For the economy, this implies that the organization is now being identified as an online transactions organization and can make tax payments online, complete financial transactions entirely online.

Such findings first suggest that the increased self-efficacy of Indian older adults in using ICTs leads to intangible benefits in terms of time savings and relying on one's abilities rather than on their social capital, which may or may not exist and which may or may not be promptly accessible. Similar findings have been reported by other scholars. Suopajärvi (2015), for example, has found that feeling and being independent, and not having to rely on others is a core part of aging, and that "[m]obility, not technology [...] key to this", highlighting concerns with regard to agency (p.120).
Second, our findings further underline that smart devices and ICTs can only be successful if older adults identify some specific benefit for their own situations, and only then will they devote their time in attaining the necessary skills. This challenges earlier findings with regard to usability being a core barrier toward the adoption of ICTs by older adults (e.g., Reisdorf \& Groselj, 2017; Choudrie et al., 2013). Instead, it stresses the importance of the technology's usefulness as older adults are primarily benefit-driven in using and adopting ICTs (Melenhorst et al., 2006). This rings true as one considers the 'time left' (Kaufman, 2010). As individuals get older, they become more and more aware of their 'time left' and seem less inclined to invest their time in activities that do not lead to significant benefits (Suopajärvi, 2015). In other words, when older adults consider they have only so many years left to live their lives and enjoy their friends and families, and as such they are less likely to sacrifice their valuable time to learn how to use an IT, especially if they are able to use different kinds of workarounds to achieve the same results (e.g., asking grandchildren to access online services for their affairs). Their benefit-driven nature was further confirmed when our participants identified additional, more tangible benefits: for example, ICTs allowed them to control costs stemming from travelling and commuting (e.g., i2) and they allowed them to increase their revenues by employing newly acquired skills in entrepreneurial activities (i1).

Our study also shows that on the job training can lead to non-pecuniary benefits, for the long-term benefits of the older adults, the organization, government and society. For instance, on the job training can lead to a reduced budget for logistics when performing financial duties. Therefore, when considering training sessions for the workforce, organizations should and can reach out to academic institutions to offer tailored training sessions that can lead to longer term benefits for all. Finally, our study shows that organizations can provide a supportive work environment that facilitates high levels of self-efficacy, which emerged due to the training offered to the volunteers, a finding like Warkentin et al. (2011), although that was in a diverse research topic, information privacy compliance.

Our study challenges previous findings with regard to the impact of health-related issues on self-efficacy. Previous studies have suggested that due to different age-related health conditions, older adults' self-efficacy may be diminished (e.g., Choudrie et al., 2010; Tyler et al., 2018). While our participants were all experiencing some health condition (e.g., heart condition) due to their age, we found no evidence that this was affecting their self-efficacy. While the participants were completing tasks individually or following the instructors' guidelines, it was only poor memory that had an impact on the outcomes. As a result, stereotyping older adults as less able to perform within computer-mediated environments may, first, indirectly influence their own perceptions 
with respect to self-efficacy (Groeppel-Klein et al., 2017), and, second, lead designers to build ICTs that do not cater for real needs and wants, but rather perceived ones (Lassen et al., 2015).

The training sessions together with an increased capability to use smart devices, transformed the Punjabi radio station into a social hub. Other Indian older adults of the community expressed their interest in participating in future training sessions, for the purpose of increasing their own understanding of smart devices, but also for socially interacting with other members of their community. On the one hand, this highlights that the provided training sessions can be a sustainable activity. On the other hand, these sessions have proven important toward supporting the social inclusion of Indian older adults, which leads to increases in psychological capital and civic participation (Formosa, 2014; Minocha et al., 2015). We consider such inclusion to be even more critical than bridging the digital divide, as ultimately the aim of such efforts is to allow older adults from ethnic minorities adults to lead happy and fulfilling lives, with and without the use of ICTs.

The major contribution of our study is that of considering the nature of the IT artefact, and particularly smart devices, which is usually missing from the digital divide discourse. Specifically, in the original Wei et al. (2011) framework, there is minimal consideration of an IT artefact. Smart devices, with their ubiquitous nature, the possibility to access the internet anywhere, anytime, in conjunction with their smaller form factor, afford use within several different contexts. This is in line with the sociomaterial conceptualisation of the IT artefact, where an IT device is not simply hardware and software, but instead a socially recognisable form that offers ways to organise work, offer support and deliver content, and where the user can shape the outcomes and be shaped by the technology (Orlikowski, 2000). This is especially true in the case of older adults, whose health conditions may not allow for the use of heavier devices, such as laptops. Commuting and travelling is often quite challenging for older adults, especially when their mobility is impacted in some way due to their personal health conditions. This suggests that health further influences the digital divide, as older adults may be unable to carry or use heavier IT devices. However, tablets are more conducive to the older adults' conditions, being lighter and more versatile. As a result, it is critical to consider their use and applications, especially when older adults are involved, and their input and involvement is desired. This in turn can help older adults to be more engaged and heard, thus supporting the reduction of the digital divide.

Our second contribution stems out of our application of the TML-based approach that is a blended approach of three learning theories with a digital divide conceptual framework. This approach allowed us to identify and understand that a learning model for training older adults should be more relevant to the lifestyle of older adults. Today, in the UK, several charities exist (e.g., University of Third Age, Tinder Foundation) that offer training to older adults. However, their training opportunities are generally standardised. In contrast, our findings show that learning that is customised to one's interests and allows participants to achieve greater outcomes by being better aligned with their requirements. In turn, this alignment can lead to increased self-efficacy among older adults, which contributes towards bridging the digital divide. This is an important finding for policy makers. Most IT training is typically provided earlier in life (OECD 2011). However, technological advances have led to the presentday devices being quite different from those of the past. As a result, today's older adults may not have had the opportunity to get exposed to, use and become familiar with the more current IT. In other words, the evolving nature of technology can only increase the digital divide because of the distance between those that use IT and those that don't use IT continuously grows (Rockmann et al., 2018). However, customised training that builds on the older adult's real needs and wants, and leverages advanced devices commonly used by other demographics is more beneficial. While older IT is often considered as more accessible, it is not always desired and can often put off older adults in fear of being seen as using 'old technology' or 'technology for the old' (Gómez, 2015).

Our third contribution is within the arena of older adults, education and ICTs use both at home and work, which is a view like Kampfen and Maurer (2018). Our study showed that education does have a role in the use of ICTs, because all our volunteers were educated, but we cannot generalise and conclude ie. offer a causal factor that this is due to any instruments used for compulsory schooling. However, at this point in time, with the principal investigator, third author, and participants being migrants and of ethnic minority origins and belonging to families where education was the reason for their migration it can be ascertained that within these cultures, education is vital, so the role of compulsory schooling cannot be generalised from this study, which emphasises the difference between this study and the studies of Kampfen and Maurer (2018) and Riddell and Song (2017) who used historical data to generalise their findings.

\section{Conclusions}

The dominant discourse around the digital divide suggests that bridging it will lead to many benefits for economies and societies. It implies that by using ICTs, older adults can remain independent, active and work for longer, which should lead to less pressure on public services, such as on the social services sector. When the older adult also belongs to an ethnic minority, the impetus is even greater since it is not only age and health that sets them apart, but also their status and their cultural differences (Mitra \& Evansluong, 2019). 
However, such a discourse inescapably implies that older adults of ethnic minorities are a burden to society and hinders a more nuanced understanding of their real needs (Lassen et al., 2015). As Neven and Peine (2017) discuss, this legitimises the large investments in ICTs for older adults, but it does not support the identification and development of ICTs that are actually useful and welcome by the older adults. This view considers ICTs to be the panacea of all issues faced by older adults, which leads to low adoption rates and ultimately a negative perception regarding ageing. As our findings show, ageing is not something that can be addressed in a sweeping fashion. For one, the realities of ageing differ greatly among pre-senior, young-old and old-old citizens, which aligns with the findings of previous researchers (Greenberg, 2009) that ageing is no longer a single stage concept. Some older adults may suffer from several illnesses, but their reflective longevity involves satisfying, healthy and active lives, without being obstructed by any of their conditions, as it occurs with most of our participants. At the same time, older adults can be quite happy in their routines, without using any kind of ICTs, and remain active and integrated within their communities using other activities, such as volunteering.

Against this background, we combine our voices with other scholars within the area of ageing and technology, and posit that what is needed is technologies that can make a significant contribution in the lives of older adults from ethnic minorities, which can be appropriated without negative connotations (e.g., they have to use old people technologies to support themselves) and allow users to focus on what is important to them (Neven \& Peine, 2017). We specifically propose the use of TMLg approaches to provide learning opportunities to those older adults with an interest in learning how to use ICTs. On the one hand, this can support them in identifying themselves whether technology has a place in their lives, and what potential benefits they can harvest, and on the other hand, attain the necessary skills and increase their self-efficacy. The TML approach was also the academic team's customised training approach for the radio station. Our study revealed that if and when organizations are approached for customised training approaches for older adults, they are willing to allow access to their workforce, but academics also have to be mindful of the time and availability of individuals when designing, developing and implementing such an approach.

Our study comes with some limitations. First, in this paper we report the findings from a fairly small case study with solely twelve participants of different ages, educational backgrounds, health conditions and family situations. As a result, the profile of the participants is more nuanced than what could normally be described as older adult or even Indian older adults. As a result, any generalisation should be approached with caution, and only where contextual factors are similar. As Jack and Anderson (2002: 473) found: "Small scale, qualitative studies in the interpretivist tradition do not allow for generalisability; their strength lies in their capacity "to provide insights, rich details and thick descriptions". Among these details are contextual factors, where we would need to refer to the cultural background of our participants, all of them being of Punjabi descent, being migrants who migrated to the UK and a way of overcoming social issues such as, social isolation, are being overcome by volunteering their time in their community to a small, community based radio station.

In addition, this study was designed around the tablet device, which offers specific possibilities. However, smart devices in general include smart watches, smartphones, and phablets among others. As a result, we consider that future studies should focus on the use of other smart devices, and possibly concentrate on identifying the requirements of different cultural groups and the outcomes stemming from such cross-cultural differences. Finally, we used a qualitative approach to reveal the meaning of actions or outcomes that can be typically measured by quantitative research in the future. Therefore, we propose that a future direction for this study is to measure some of the actions or outcomes of this study; thereby, identifying the causes of the digital divide and ways of overcoming them.

Open Access This article is licensed under a Creative Commons Attribution 4.0 International License, which permits use, sharing, adaptation, distribution and reproduction in any medium or format, as long as you give appropriate credit to the original author(s) and the source, provide a link to the Creative Commons licence, and indicate if changes were made. The images or other third party material in this article are included in the article's Creative Commons licence, unless indicated otherwise in a credit line to the material. If material is not included in the article's Creative Commons licence and your intended use is not permitted by statutory regulation or exceeds the permitted use, you will need to obtain permission directly from the copyright holder. To view a copy of this licence, visit http://creativecommons.org/licenses/by/4.0/.

\section{References}

Adler, P., \& Adler, P. (2012). Expert voice in Baker, S. E. and Edwards, R. How many qualitative interviews are enough? National Center for research methods review discussion paper, p.8-11. Available at: http://eprints.ncrm.ac.uk/2273/. Viewed: January 15, 2020.

Agarwal, R., Animesh, A., \& Prasad, K. (2009). Social interactions and the digital divide: Explaining variations in internet use. Information Systems Research., 20(2), 277-294.

Agudo, S., Pascual, M. A., \& Fombona, J. (2012). Uses of digital tools among the elderly. Comunicar, 20(39), 193e201-193e201. https:// doi.org/10.3916/C39-2012-03-10.

Alam, K., \& Imran, S. (2015). The digital divide and social inclusion among refugee migrants: A case in regional Australia. Information Technology \& People, 28(2), 344-365.

Alavi, M., \& Leidner, D. E. (2001). Research commentary: Technologymediated learning: A call for greater depth and breadth of research. Information Systems Research., 12(1), iii-117. 
Atkinson, A.B. (1998). Social exclusion, poverty and unemployment. In A.B. Atkinson, \& J. Hills (Eds.), Exclusion, employment and opportunity, centre for analysis of social exclusion. London School of Economics (case paper no. 4).

Avgerou, C., \& Madon, S. (2005). Information society and the digital divide problem in developing countries. In J. Berleur \& C. Avgerou (Eds.), Perspectives and policies on ICT in society (pp. 205-218). Springer.

Bandura, A. (1977). Self-efficacy: Toward a unifying theory of behavioral change. Psychological Review, 84(2), 191-215.

Bandura, A. (1986). Social foundations of thought and action. Prentice Hall.

Bandura, A. (1989). Regulation of cognitive processes through perceived self-efficacy. Developmental Psychology, 25(5), 729-735.

Bandura, A., \& Cervone, D. (1986). Differential engagement of selfreactive influences in cognitive motivation. Organizational Behavior \& Human Decision Processes., 38(1), 92-113.

Becker, H.S. (2012). Expert voice in baker, S. E. and Edwards, R. How many qualitative interviews are enough? National Center for research methods review discussion paper, p.15. Available at: http:// eprints.ncrm.ac.uk/2273/. Viewed: January 15, 2020.

Benitez, J. L. (2006). Transnational dimensions of the digital divide among Salvadoran immigrants in the Washington DC metropolitan area. Global Networks, 6(2), 181-199.

Beyerbach, B., Walsh, C., \& Vannatta, R. (2001). From teaching technology to using technology to enhance pre-service teacher learning: Pre-service teachers' changing perceptions of technology infusion. Journal of Technology and Teacher Education, 9(1), 105-127.

Bong, M., \& Skaalvik, E. M. (2003). Academic self-concept and selfefficacy: How different are they really? Educational Psychology Review, 15, 1-40.

Burchardt, T., Le Grand, J., \& Piachaud, D. (1999). Social exclusion in Britain 1991-1995. Social Policy and Administration, 33(3), 227 244

Caggiano, D. M., Jiang, Y., \& Parasuraman, R. (2006). Aging and repetition priming for targets and distracters in a working memory task. Aging, Neuropsychology, and Cognition., 13(3/4), 552-573.

Cattan, M., White, M., Bond, J., \& Learmouth, A. (2005). Preventing social isolation and loneliness among older people: A systematic review of health promotion interventions. Ageing \& Society, 25, 41-67.

Ching, C. C., Basham, J. D., \& Jang, E. (2005). The legacy of the digital divide, gender, socioeconomic status, and early exposure as predictors of full-Spectrum technology use among young adults. Urban Education., 40(4), 394-341.

Choudrie, J., Ghinea, G., \& Songonuga, V. N. (2013). Silver surfers, egovernment and the digital divide: An exploratory study of UK local authority websites and older citizens. Interacting with Computers, 25(6), 417-442.

Choudrie, J., Grey, S., \& Tsitsianis, N. (2010). Evaluating the digital divide: The Silver Surfer's perspective. Electronic Government., $7(2), 148-167$.

Choudrie, J., Pheeraphuttranghkoon, S., \& Davari, S. (2018). The digital divide and older adult population adoption use and diffusion of Mobile phones: A quantitative study. Information Systems Frontiers., 1-23.

Choudrie, J., \& Vyas, A. (2014). Silver surfers adopting and using Facebook? A quantitative study of Hertfordshire, UK: Applied to organizational and social change. Technological Forecasting and Social Change, 89, 293-305.

Choudrie, J., \& Zamani, E. D. (2016). Understanding individual user resistance and workarounds of Enterprise social networks: The case of service ltd. Journal of Information Technology, 31(2), 130-151.

Cruz-Jesus, F., Oliviera, T., \& Bacao, F. (2012). Digital divide across the European Union. Information \& Management., 49, 278-291.
Dacko, G., \& Spalteholz, C. (2014). Upgrading the city: Enabling intermodal travel behaviour. Technological Forecasting and Social Change, 89, 222-235.

de Haan, A (1999). Social exclusion: Towards an holistic understanding of deprivation, in World development report 2001 forum on inclusion, justice and poverty reduction, prepared for the world development report 2001 forum on 'Inclusion, Justice and Poverty Reduction'.

de Haan, A. (2001). 'Social exclusion: Enriching the understanding of deprivation', in world development report 2001 forum on inclusion, justice and poverty reduction.

Dewan, S., \& Riggins, F. J. (2005). The digital divide: Current and future research directions. Journal of Association of Information Systems., 6(12), 298-337.

Eisenhardt, K. M. (1989). Building theories from case study research. Academy of Management Review, 14(4), 532-550.

Fisk, A. D., Rogers, W. A., Czaja, S. J., Charness, N., \& Sharit, J. (2004). Designing for older adults: Principles and creative human factors. CRC Press.

Formosa, M. (2014). Four decades of universities of the third age: Past, present, future. Ageing and Society, 34(1), 1e25. https://doi.org/10. 1017/S0144686X12000797.

Ghahramani, F., \& Wang, J. (2019). Impact of smartphones on quality of life: A health information behavior perspective. Information Systems Frontiers. June., 1-16.

Given LM. (2016). 100 Questions (and answers) about qualitative research. Sage.

Glaser, B. G., \& Strauss, A. (1967). The discovery of grounded theory: Strategies for qualitative research. Aldine Publishing Co..

Gómez, D. L. (2015). Little arrangements that matter. Rethinking autonomy-enabling innovations for later life. Technological Forecasting and Social Change, 93, 91-101.

Gonzalez, C., Fanjul, C., \& Cabezuelo, F. (2015). Use, consumption and knowledge of new technologies by elderly people in France, United Kingdom and Spain. Comunicar, 23(45), 19e28-19e28. https://doi. org/10.3916/C45-2015-02.

Goodall, K. T., Ward, P. R., \& Newman, L. A. (2010). Use of information and communication technology to provide health information: What do older migrants know, and what do they need to know? Quality in Primary Care, 18(1), 27-32.

Gordon, W., \& Langmaid, R. (1988). Qualitative market research: A Practitioner's and Buyer's guide. Gower.

Grady, M. P. (1998). Qualitative and action research: A practitioner handbook. Phi Delta Kappa Educational Foundation.

Greenberg, S. (2009). A profile of older Americans. Administration on Aging. USA Department of Health Human Services, Washington DC, USA.

Groeppel-Klein, A., Helfgen, J., Spilski, A., \& Schreiber, L. (2017). The impact of age stereotypes on elderly consumers' self-efficacy and cognitive performance. Journal of Strategic Marketing, 25(3), 211225.

Gupta, S., \& Bostrom, R. P. (2009). Technology-mediated learning: A comprehensive theoretical model. Journal of the Association of Information Systems., 10(9), 686-714.

Hiddenlondon (2018). London's local demographics: Highlights from the 2011 census. Available at: http://hidden-london.com/miscellany/ demographics/. Viewed August 15, 2018.

Hill, R., Betts, L. R., \& Gardner, S. E. (2015). Older adults' experiences and perceptions of digital technology: (dis)empowerment, wellbeing, and inclusion. Computers in Human Behavior, 48, 415-423.

Hill, W., \& Beatty, S. E. (2011). A model of adolescents' online consumer self-efficacy (OCSE). Journal of Business Research., 64(10), 1025 1033.

Horrigan, J., \& Rainie, L. (2006). The Internet's growing role in Life's major moments. Pew Internet and American Life Project. 
Hwang, H., \& Nam, S. J. (2017). The digital divide experienced by older consumers in smart environments. International Journal of Consumer Studies, 41(5), 501-508.

Jack, S. L., \& Anderson, A. R. (2002). The effects of Embeddedness on the entrepreneurial process. Journal of Business Venturing., 17, 467-487.

Johnson, R. D., \& Marakas, G. M. (2000). Research report: The role of behavioral modeling in computer skills acquisition: Toward refinement of the model. Information Systems Research, 11(4), 402-417.

Jonassen, D. H. (1993). The Trouble with Learning Environments. Educational Technology, 33(1), 35-37.

Jones, B. D., \& Bayen, U. J. (1998). Teaching older adults to use: Recommendations based on cognitive aging research. Educational Gerontology., 24, 675-689.

Joyce, M., \& Kirakowski, J. (2014). Measuring confidence in internet use: The development of an internet self-efficacy scale. In A. Marcus (Ed.), Design, user experience, and usability. Theories, methods and tools for designing the user experience. 8517:250260. SpringerVerlag.

Kampfen, F., \& Maurer, J. (2018). Does education help old dogs learn new tricks? The lasting impact of early-life education on technology use among older adults. Research Policy, 47(6), 1125-1132.

Kaufman, S. R. (2010). Time, clinic technologies, and the making of reflexive longevity: The cultural work of time left in an ageing society. Sociology of Health \& Illness, 32(2), 225-237.

Kauffman, R. J., \& Techatassanasoontor, A. (2005). Is there a global digital divide for digital wireless phone technologies?. Association of Information Systems 6(12). https://doi.org/10.17705/1jais.00073

Kirschner, P. A., Sweller, J., \& Clark, R. E. (2006). Why minimal guidance during instruction does not work: An analysis of the failure of constructivist, discovery, problem-based, experiential, and inquirybased teaching. Educational Psychologist, 41, 75-86.

Koh, J. H. L. (2011). Computer skills instruction for pre-service teachers: A comparison of three instructional approaches. Computers in Human Behavior, 27, 2392-2400.

Kumar, V., Aaker, D. A., \& Day, G. S. (2002). Essentials of marketing research (2nd ed.). Wiley.

Kuo, Y. C. (2018). An exploratory study of minority students' technology usage and perceptions of technology: Nontraditional adult students in technology-based environments. Journal of Research on Technology in Education, 50(4), 350-364.

Lagana, L. (2008). Enhancing the attitudes and self-efficacy of older adults toward computers and the internet: Results of a pilot study. Educational Gerontology, 34, 831-843. https://doi.org/10.1080/ 03601270802243713.

Lassen, A. J., Bønnelycke, J., \& Otto, L. (2015). Innovating for active ageing in a public-private innovation partnership: Creating doable problems and alignment. Technological Forecasting and Social Change, 93, 10-18.

Lee, C., Myrick, R., Ambrosio, L. A. D., Coughlin, J. F., \& de Weck, O. L. (2013). Older adults' experiences with technology: Learning from their voices. HCI International 2013 - Posters' Extended Abstracts 373, 251-255.

Leidner, D. E., \& Jarvenpaa, S. L. (1995). The use of information technology to enhance management school education: A theoretical view. MIS Quarterly, 3(19), 265-291.

Lin, Y. C., Liang, J. C., Yang, C. J., \& Tsai, C. C. (2013). Exploring middle-aged and older adults' sources of internet self-efficacy: A case study. Computers in Human Behavior, 29(6), 2733-2743.

Lleras-Muney, A., \& Lichtenberg, F. (2002). The effect of education on medical technology adoption: Are the more educated more likely to use new drugs? NBER working paper \#9185.

MacArthur Foundation (2012). Digital Media and Learning. Available at: https://files.eric.ed.gov/fulltext/ED536083.pdf. Viewed: December 2, 2019.
Marikyan, D., Papagiannidis, S., \& Alamanos, E. (2019). A systematic review of the smart home literature: A user perspective. Technological Forecasting and Social Change, 138, 139-154.

Martinez-Garcia, E. (2013). Technological progress is key to improving world living standards. Federal Reserve Bank Dallas Econ. Lett., 8.

Martínez-Pecino, R., Delerue, A., \& Silva, P. (2013). Portuguese older people and the internet: Interaction, uses, motivations, and obstacles. The European Journal of Communication Research, 38(4), 331346.

Mayer, R. E. (2004). Should there be a three-strikes rule against pure discovery learning? American Psychologist, 59(1), 14-19.

Melenhorst, A. S., \& Bouwhuis, D. G. (2004). When do older adults consider the internet? An exploratory study of benefit perception. Gerontechnology, 3, 89-101.

Melenhorst, A. S., Rogers, W., \& Bouwhuis, D. G. (2006). Older adults' motivated choice for technological innovation: Evidence for benefitdriven selectivity. Psychology and Aging, 21(1), 190-195.

Miles B, Huberman AM. (2009). Qualitative data analysis. Sage Publications Ltd.

Minocha, S., McNulty, C., \& Evans, S. (2015). Imparting digital skills to people aged 55 years and over in the UK. Milton Keynes, UK: The Open University Available at: http://oro.open.ac.uk/44009/.

Mitra, A., \& Evansluong, Q. (2019). Narratives of integration: Liminality in migrant acculturation through social media. Technological Forecasting and Social Change, 145, 474-480.

NetLingo (2021). Silver surfers. Definition Available from: http://www. netlingo.com/word/silver-surfer.php. Viewed: January 5, 2021.

Neven, L., \& Peine, A. (2017). From triple win to triple sin: How a problematic future discourse is shaping the way people age with technology. Societies, 7(3), 26.

Niehaves, B., \& Plattfaut, R. (2014). Internet adoption by the elderly: Employing IS technology acceptance theories for understanding the age-related digital divide. European Journal of Information Systems, 23(6), 708-726.

Norris, P. (2001). Digital divide: Civic engagement, information poverty, and the internet worldwide. Cambridge University Press.

Notley, T. M., \& Foth, M (2008) Extending Australia's digital divide policy: An examination of the value of social inclusion and social capital policy frameworks. Australian Social Policy 7. Available at: http://eprints.qut.edu.au/12021/1/12021b.pdf. Viewed: February 14, 2017.

OECD (2018) Supporting employers to retain and hire older workers in the United States, In Ageing and Employment Policies: United States 2018: Working Better with Age and Fighting Unequal Ageing, OECD Publishing, Paris, https://doi.org/10.1787/ 9789264190115-5-en.

Orlikowski, W., \& Baroudi, J. J. (1991). Studying information Technology in Organizations: Research approaches and assumptions. Information Systems Research, 2(1), 1-28.

Orlikowski, W. J. (2000). Using technology and constituting structures: A practice lens for studying technology in organizations. Organization Science, 11(4), 404-428.

Östlund, B., Olander, E., Jonsson, O., \& Frennert, S. (2015). STSinspired design to meet the challenges of modern aging. Welfare technology as a tool to promote user driven innovations or another way to keep older users hostage? Technological Forecasting and Social Change, 93, 82-90. https://doi.org/10.1016/j.techfore.2014. 04.012 .

Peine, A., Faulkner, A., Jæger, B., \& Moors, E. (2015). Science, technology and the grand challenge of ageing - Understanding the sociomaterial constitution of later life. Technological Forecasting and Social Change, 93, 1-19.

Pellegrino, J. W., \& Altman, J. E. (1997). Information technology and teacher preparation: Some critical issues and illustrative solutions. Peabody Journal of Education, 72(1), 89-121. 
Piper, A. M., Brewer, R., \& Cornejo, R. (2016). Technology learning and use among older adults with late-life vision impairments. Universal Access in the Information Society pp. 1-13. https://doi.org/10.1007/ s10209-016-0500-1.

Reisdorf, B. C., \& Groselj, D. (2017). Internet (non-)use types and motivational access: Implications for digital inequalities research. New Media \& Society, 19(8), 1157-1176.

Renkl, A., \& Atkinson, R. K. (2003). Structuring the transition from example study to problem solving skill acquisition: A cognitive load perspective. Educational Psychologist, 38(1), 15-22.

Riddell, W.C., Song, X. (2017). The role of education in technology use and adoption. ILR Rev.

Rockmann, R., Gewald, H., \& Haug, M. (2018). Equal access for everyone? a digital divide cascade for retired senior citizens. Research Papers, 30. https://aisel.aisnet.org/ecis2018_rp/30.

Rogers, E. (2003). Diffusion of innovations (5th ed.). Free Press.

Rogers, W. A., Fisk, A. D., \& Hertzog, C. (1994). Do ability-performance relationship differentiate age and practice effects in visual search? Journal of experimental psychology. Learning, Memory and Cognition., 20, 710-738.

Ross, A., \& Ernstberger, K. E. (2006). Benchmarking the IT productivity paradox: Recent evidence from the manufacturing sector. Mathematical and Computer Modelling. 44, (1-2), 30-42.

Saunders, M. N. K. (2012). Choosing research participants' in Symon, G. and Cassell, C. (eds). Qualitative organizational research: Core methods and current challenges. Sage: 35-52.

Schaie, K. W., \& Willis, S. L. (2002). Adult development and aging (5th ed.), Prentice-Hall, New York.

Schleife, K. (2010). What really matters: Regional versus individual determinants of the digital divide in Germany. Research Policy, 39, $173-185$.

Selwyn, N., Gorard, S., \& Furlong, J. (2006). Adult learning in the digital age (pp. 7-12). Routledge.

Selwyn, N., Gorard, S., Furlong, J., \& Madden, L. (2003). Older adults' use of information and communications technology in everyday life. Ageing \& Society., 23, 561-582.

Sen, A. (2000). Social exclusion: Concept, application, and scrutiny, Asian Development Bank. Available at: http://www.gsdrc.org/ document-library/social-exclusion-concept-application-andscrutiny/. Viewed: February 2, 2017.

Silver, H. (1994). Social exclusion and social solidarity: Three paradigms. International Labour Review, 133, 531-578.

Slavin, R. E. (1990). Cooperative learning theory, research and practice. Prentice-Hall.

Snider, S. L. (2002). Exploring technology integration in a field-based teacher education program: Implementation efforts and findings. Journal of Research on Technology in Education, 34(3), 230-249.

Suopajärvi, T. (2015). Past experiences, current practices and future design: Ethnographic study of aging adults' everyday ICT practicesAnd how it could benefit public ubiquitous computing design. Technological Forecasting and Social Change, 93, 112-123.

Tsatsou, P. (2011). Digital divides revisited: What is new about divides and their research?. Media, Culture \& Society 33(2), pp. 317-331. Available at: http://mcs.sagepub.com/cgi/doi/10.1177/ 0163443710393865 (Viewed 27 June 2013).

Tyler, M., Simic, V., \& De George-Walker, L. (2018). Older adult internet super-users: Counsel from experience. Activities, Adaptation \& Aging, 1-12.

United Nations Development Programme. (2001). Human development report 2001: Making new technology work for human development. Oxford University Press.

Urquhart, C. (2012). Grounded theory for qualitative research. A practical guide. SAGE Publications Ltd..

Urquhart, C. (2013). Grounded theory for qualitative research: A practical guide. Sage.
Van Dijk, J., \& Hacker, K. (2003). The digital divide as a complex and dynamic phenomenon. The Information Society, 19(4), 315-326.

Vroman, K. G., Arthanat, S., \& Lysack, C. (2015). Who over 65 is online? Older adults' dispositions toward information communication technology. Computers in Human Behavior, 43, 156-166.

Walsham, G. (1995). Interpretive case studies in IS research: Nature and method. European Journal of Information Systems, 4(2), 74-81.

Walsham, G. (2006). Doing interpretive research. European Journal of Information Systems, 15, 320-330.

Wang, C., Pang, C., Moffatt, K., Leung, R., \& McGrenere, J. (2019). Supporting older adults in the use of smart devices for personal health management. ASSETS 2019 - 21st international ACM SIGACCESS conference on computers and accessibility. October, 24, 615-617.

Warkentin, M., Johnston, A. C., \& Shropshire, J. (2011). The influence of the informal social learning environment on information privacy policy compliance efficacy and intention. European Journal of Information Systems., 20(11), 267-284.

Warschauer M. (2003). Dissecting the "digital divide": A case study in Egypt. The Information Society, 19(4), 297.

Warschauer, M. (2004). Technology and social inclusion: Rethinking the digital divide.

Weber, G., Power, C., Petrie, H., \& Darzentas, J. (2015). Learning beyond the classroom: For and about older and disabled people. In the Proceedings of the IFIP Conference on Human-Computer Interaction (pp. 665-666). Springer.

Wei, K. K., Teo, H.-H., Chan, H. C., \& Tan, B. C. Y. (2011). Conceptualizing and testing a social cognitive model of the digital divide. Information Systems Research, 22(1) March, 170-187.

Welch, F. (1970). Education in production. Journal of Political Economy, $78,35-59$.

Whipple, W. R. (1987). Collaborative learning-recognizing it when we see it. American Association of Higher Education Bulletin., 40, 3-7.

Whitbourne, S. K. (2001). Adult development and aging: Biopsychological perspectives. John Wiley \& Sons.

Whitford, M. (1998). Market in motion. Hotel and Motel Management, 4, $41-43$.

Wood, J. (2018). These countries are gaining the most by employing older workers. Available at: https://www.weforum.org/agenda/ 2018/08/older-workers-employment-oecd-economies. Viewed. November 28, 2018. Published. August 17.

Wozniak, G. D. (1984). The adoption of interrelated innovations: A human capital approach. Review of Economics and Statistics., 66, 70 79.

Wozniak, G. D. (1987). Human capital, information, and the early adoption of new technology. Journal of Human Resources., 22, 101-112.

Wyatt, S. M. (2003). Non-users also matter: The construction of users and non-users of the internet, in Now users matter: The co-construction of users and technology, Ed. Oudshoorn, N., Pinch, T. MIT Press: 67-79.

Yarusso, L. (1992). Constructivism vs. objectivism. Constructivism vs. Objectivism. Performance \& Instruction, 31(4), 7-9.

Yu-Huei, C., Ja-Shen, C., \& Ming-Chao, W. (2019). Why do older adults use wearable devices: A case study adopting the senior technology acceptance model (STAM). PICMET 2019 - Portland International Conference on Management of Engineering and Technology: Technology Management in the World of Intelligent Systems, Proceedings. August 2019, Article number 8893767.

Zuboff, S. (1988). In the age of the smart machine: The future of work and power. Harvard Business School.

Zulkifli, A. N., Ahmad, M., Abu Bakar, J. A., \& Che Mat, R. (2015). Examining the influence of interactive persuasive learning among elderly. ARPN Journal of Engineering and Applied Sciences, 10(3), $1145-1153$. 
Publisher's Note Springer Nature remains neutral with regard to jurisdictional claims in published maps and institutional affiliations.

Professor Jyoti Choudrie holds the position of Professor of Information Systems at University of Hertfordshire. She has extensive years' experience specialising in investigating the social inclusion and adoption of Information and Communications Technologies on society's 'marginal groups', the adoption, use and diffusion of innovative Information and Communication Technologies in Small to Medium Size Enterprises and large organizations. This is based upon the principles and mechanisms of variables taken from the theories of diffusion, adoption, usage and implementation in the social, organisational and government realms and how they can be brought to fruition using modern internet related technologies; for instance, Broadband, Smartphones and online social networks to guide and improve individuals experiences of modern technology. This was achieved due to sponsored research funding schemes-Royal Academy of Engineering, Microsoft and Knowledge Transfer Partnerships and consultancy projects with organizations such as, British Telecom and AoL. To ensure that her expertise remains in the area, she has written for established journals such as, European Journal of Information Systems (EJIS), Journal of Information Technology, Technological Forecasting and Social Change and Journal of Business Research.
Mr. Chike Obuekwe is a doctoral candidate at University of Hertfordshire Business School. He is examining whether older adults use Twitter or Facebook more. For this study, he is using a quantitative approach for analysis. He is also knowledgeable in the data collection techniques of interviews and focus groups.

Dr. Efpraxia Zamani has broad research interests relating to the organizational and social aspects of information systems. She is particularly interested in post-adoption user behaviour, enterprise information systems and ICT4D. For her PhD, she considered user sensemaking with portable IT artefacts, such as tablets. More specifically, she has looked into episodes of disillusionment, and how users develop their own accommodating practices for the purposes of appropriating an IT artefact. Her research work has been presented in numerous conferences and has been published in journals such as the Journal of Information Technology, Government Information Quarterly and the International Journal of Electronic Commerce. 